PCS (24.9 vs. 24.7, $p=0.210$ ) and SF12-MCS (19.1 vs. $18.9, p=0.532$ ) scores at 12 months.

During follow-up, $7.4 \%$ of ADA patients initiated another biologic and $23.7 \%$ of patients in the nbDMARD group initiated biologic treatment $(p<0.001)$.

Conclusions: AS patients initiating ADA in Canadian routine clinical care have significantly greater disease severity and impaired quality of life at baseline compared with those initiating non-biologic treatment. Treatment with ADA for 12 months resulted in greater reduction in the prevalence of EAMs and a greater reduction in disease severity scores compared to treatment with non-biologic agents.

Acknowledgements: JSS Medical Research, Montreal, Canada

Disclosure of Interest: L. Bessette Consultant for: Amgen, BMS, Janssen, Roche, UCB, AbbVie, Pfizer, Celgene, Lilly, Novartis, Speakers bureau: Amgen, BMS, Janssen, Roche, UCB, AbbVie, Pfizer, Merck, Celgene, Lilly, Novartis, M. Khraishi Consultant for: AbbVie, Speakers bureau: AbbVie, A. Chow Consultant for: AbbVie, Amgen, BMS, Celgene, Janssen, Lilly, Merck, Novartis, Pfizer, Roche, Speakers bureau: AbbVie, BMS, Janssen, Pfizer, Takeda, V. Pavlova Grant/research support from: UCB, Consultant for: Amgen, Abbvie, BMS, Janssen, Lilly, Merk, Novartis, Roche, UCB, Pfizer, Speakers bureau: Amgen, Abbvie, BMS, Janssen, Lilly, Merk, Novartis, Roche, UCB, Pfizer, S. Silverberg Consultant for: AbbVie, Janssen, J. Stewart Consultant for: Pfizer, Abbvie, Amgen, Celgene, Roche, Novartis, V. Remple Shareholder of: AbbVie, Employee of: AbbVie DOI: 10.1136/annrheumdis-2018-eular.3769

\section{SAT0291 CREATION OF A EUROPEAN DATABASE OF PATIENTS WITH AXIAL SPONDYLOARTHRITIS TREATED IN CLINICAL PRACTICE- INITIAL, PRELIMINARY FINDINGS FROM THE EUROSPA RESEARCH NETWORK COLLABORATION}

L.M. Ørnbjerg, M. Østergaard, F. Onen, G. Can, Z. Rotar, M. Tomsic, B. Gudbjornsson, A.J. Geirsson, M.J. Santos, A. Barcelos, D. Nordström, K. Aaltonen, M.J. Nissen, A. Ciurea, E.K. Kristianslund, T. Kvien, C. Codreanu, E.M. Hauge, L. Jacobsson, H. Mann, G. Jones, F. lannone, M.V. Hernandez, I. van der Horst-Bruinsma, L.H. Hyldstrup, N.S. Krogh, M.L. Hetland. EuroSpA Research Collaboration Network, Coordinating Centre, On behalf of the DANBIO, TURKBIO, biorx.si, ICEBIO, Reuma.pt, ROB-FIN, SCQM, NOR-DMARD, RRBR, ARTIS, ATTRA, BSRBR-AS, GISEA, BIOBADASER and ARC registries, Copenhagen, Denmark

Background: A research network collaboration of 15 European registries sharing data on patients with spondyloarthitis (SpA), "EuroSpA", has recently been created to strengthen research capabilities in the real world setting ${ }^{1}$. Here we present the first results from the collaboration.

Objectives: To investigate the feasibility of creating a common database for axial $\mathrm{SpA}(\mathrm{axSpA})$, including non-radiographic SpA and ankylosing spondylitis, within the EuroSpA collaboration and to conduct proof-of-concept analyses by investigation of baseline characteristics, disease activity at baseline and after 6 months, and crude 12 months' Tumour Necrosis Factor inhibitor (TNFi) retention rate in patients with axSpA initiating TNFi.

Methods: A common data model was agreed upon by the EuroSpA Scientific Committee. Virtual meetings between the EuroSpA and registry data managers clarified data availability and structure. This was followed by upload of anonymized data through the secure Virtual Private Network pipelines to the EuroSpA server. Baseline characteristics and disease activity at baseline and after 6 months were investigated with non-parametric descriptive statistics. Kaplan-Meier estimation was used to investigate TNFi retention rates.

Results: By January 8th 2018, four of the 15 registries participating in EuroSpA had completed data upload to the EuroSpA database resulting in 6756 patients with AxSpA in a pooled dataset. Baseline characteristics of the participating registry populations at initiation of first TNFi are shown in Table I. Crude 12 months' TNFi retention rate varied from $66 \%-85 \%$ for 1 st TNFi and $61 \%-78 \%$ for 2 nd TNFi (see figure 1). For the pooled dataset crude 12 months' TNFi retention rates were $73 \%$ and $66 \%$ for the $1 \mathrm{st}$ and $2 \mathrm{nd} \mathrm{TNFi}$, respectively.
Abstract SAT0291 - Table 1. Baseline demographic and disease characteristics of patients with social spondyloarthritis registered in four registries participating in the EuroSpA Research Network Collaboration.

\begin{tabular}{|c|c|c|c|c|c|c|c|c|}
\hline & \multicolumn{2}{|c|}{$\begin{array}{l}\text { DAsDSO (Denumb) } \\
\mathrm{N}-3949\end{array}$} & \multicolumn{2}{|c|}{$\begin{array}{l}\text { Bivox si (Slonemin) } \\
\mathrm{N}-616\end{array}$} & \multicolumn{2}{|c|}{$\begin{array}{l}\text { TURK :110 (Tukey) } \\
N-1977\end{array}$} & \multicolumn{2}{|c|}{$\begin{array}{l}\text { ICEMIO (kelund) } \\
\text { N-315 }\end{array}$} \\
\hline Apt ysosis & \multicolumn{2}{|l|}{$4(93-50)$} & \multicolumn{2}{|l|}{$45\{36-55\}$} & \multicolumn{2}{|l|}{$37(30-45)$} & \multicolumn{2}{|l|}{$43(34-59)$} \\
\hline Manken(y) & \multicolumn{2}{|l|}{$2353(61)$} & \multicolumn{2}{|l|}{$396(64)$} & \multicolumn{2}{|l|}{$1231(62)$} & \multicolumn{2}{|l|}{$210(67)$} \\
\hline HLA $B 27, \mathrm{D}(9)$ & \multicolumn{2}{|l|}{$2005(\infty 2)$} & \multicolumn{2}{|l|}{$4044(50)$} & \multicolumn{2}{|l|}{$720(62)$} & \multicolumn{2}{|l|}{$78(91)$} \\
\hline 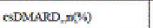 & \multicolumn{2}{|l|}{$1071(20)$} & \multicolumn{2}{|l|}{$93(15)$} & \multicolumn{2}{|l|}{372 (19) } & \multicolumn{2}{|l|}{$6(22)$} \\
\hline Diseane duration, years & \multicolumn{2}{|l|}{10.0} & \multicolumn{2}{|l|}{$5(\mathbf{1}-13)$} & \multicolumn{2}{|l|}{$3(1-3)$} & \multicolumn{2}{|l|}{$3(0-11)$} \\
\hline Smoking sthess, ctereas, in & \multicolumn{2}{|l|}{$1157(33)$} & \multicolumn{2}{|l|}{$135,(22)$} & \multicolumn{2}{|l|}{$63(41)$} & \multicolumn{2}{|l|}{5000} \\
\hline 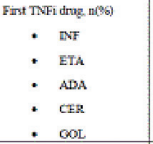 & \multicolumn{2}{|l|}{$\begin{array}{l}1371(66) \\
542(1+4) \\
1091(28) \\
2720) \\
572(15) \\
\end{array}$} & \multicolumn{2}{|l|}{$\begin{array}{l}96(15) \\
139(23) \\
768(44) \\
7(13) \\
106(17)\end{array}$} & \multicolumn{2}{|l|}{$\begin{array}{l}327(27) \\
579(29) \\
547(27) \\
59(6) \\
25(11)\end{array}$} & \multicolumn{2}{|l|}{$\begin{array}{l}256(62) \\
28(10) \\
6(2) \\
0(0) \\
23(6)\end{array}$} \\
\hline 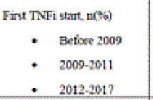 & \multicolumn{2}{|l|}{$\begin{array}{l}963059 \\
360022) \\
2025(53)\end{array}$} & \multicolumn{2}{|l|}{$\begin{array}{l}112(15) \\
179(29) \\
324(59)\end{array}$} & \multicolumn{2}{|l|}{$\begin{array}{l}159 \% \\
211(11) \\
1659(14)\end{array}$} & \multicolumn{2}{|l|}{$\begin{array}{l}115(67) \\
45(15) \\
154(48)\end{array}$} \\
\hline & Baverime & 6 mouth & Brweline & 6 mosuths & Baselise & 6 mornth & Brssline & 6 manths \\
\hline BASDAI mm & $60(47-73)$ & $28(13-49)$ & $70(37-80)$ & $z(35-47)$ & $30(36-68)$ & $16(s-32)$ & $\omega(46-75)$ & $20,(2,-9)$ \\
\hline BASF, nun & $49(32-67)$ & $25(6-4)$ & 58 (40-70-73) & $25(12-46)$ & $31(17-51)$ & $10(0-277)$ & $43(32-57)$ & $16(7.33)$ \\
\hline VAS Pistent globsil man & $72(55-65)$ & $20(12, \ldots)$ & $70(60.60)$ & $40(20.50)$ & $70(51-75)$ & $27(10-50)$ & $67(30-5 t)$ & $16(0 .-40)$ \\
\hline VAS Pria , max & $66(49.79)$ & $25(10-56)$ & $70(50-50)$ & $30(10-50)$ & $72(50-80)$ & $28(10-50)$ & $65(46-7 m)$ & $14(6: 53)$ \\
\hline
\end{tabular}
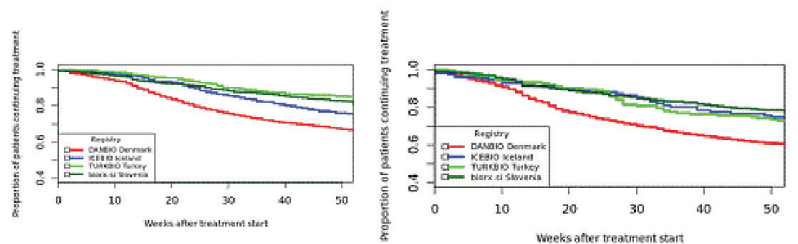

Conclusions: Preliminary analyses showed differences across European regis tries regarding baseline characteristics and crude retention rates in axSpA patients initiating TNFi. These initial, preliminary analyses demonstrate that the creation of a large European database of axSpA patients treated in routine care based on a common data model is feasible, offering important opportunities for future research.

\section{REFERENCE:}

[1] Ann Rheum Dis 2017;(suppl. 2):65

Acknowledgements: The authors acknowledge Novartis Pharmaceuticals AG for financial support and Natasha Pillai and Carol Lines from QuintilesIMS and Craig Richardson from Novartis Pharmaceuticals AG for their assistance in setting up the EuroSpA collaboration.

Disclosure of Interest: L. Ørnbjerg: None declared, M. Østergaard: None declared, F. Onen: None declared, G. Can: None declared, Z. Rotar: None declared, M. Tomsic Consultant for: AbbVie, Eli Lilly, Johnson and Johnson, Medis, MSD, Novartis, Pfizer and Roche, B. Gudbjornsson: None declared, A Geirsson: None declared, M. Santos: None declared, A. Barcelos: None declared D. Nordström Consultant for: AbbVie, Celgene, BMS, Lilly, MSD, Novartis, Pfizer UCB, K. Aaltonen: None declared, M. J. Nissen: None declared, A. Ciurea: None declared, E. Kristianslund: None declared, T. Kvien Grant/research support from: AbbVie, Biogen, BMS, Boehringer Ingelheim, Celgene, Celltrion, Eli Lilly, Epirus, Hospira, Merck-Serono, MSD, Mundipharma, Novartis, Orion Pharma, Hospira/ Pfizer, Sandoz, UCB, C. Codreanu: None declared, E.-M. Hauge: None declared, L. Jacobsson: None declared, H. Mann: None declared, G. Jones: None declared, F. lannone: None declared, M. V. Hernandez: None declared, I. van der HorstBruinsma: None declared, L. H. Hyldstrup: None declared, N. S. Krogh: None declared, M. Hetland Grant/research support from: AbbVie, Biogen, BMS, CellTrion, MSD, Orion, Pfizer, Samsung, UCB DOI: 10.1136/annrheumdis-2018-eular.2053 